\title{
IDÉIAS
}

\section{EUA não está longe de um parlamentarismo}

Prof. James Young

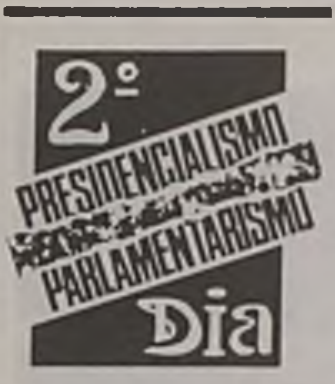

Há duzentos anos atrás, nesta época do ano, delegados dos novos Estados Unidos estavam se preparando para partirem à Philadelphia para escrever uma nova Constituição. A tarefa deles não era fácil. A nova Nação tinha pouco mais de dez anos. Após a Revolução Americana estava em crise de regime, a autoridade do governo central estava sendo destespeitada, os Estados que lutaram juntos pela independência estavam se desagregando, estavam formando exércitos, falava-se em guerras entre os Estados, e as contendas comerciais prosseguiam. Os delegados levaram três meses para escrever a nova constituição e um pouco mais do que isso para convencer os Estados a ratificá-la.

Como um estudioso de história constitucional e da presidência dos EUA, bem como cidadão americano sinto-me muito honrado pelo convite de estar aqui não tanto para ensinar, mas para aprender com vocês, c acredito que o trabalho dos brasileiros vai ser muito mais dificil, para claborar a sua nova constituição do que foi o trabalho dos fundadores dos EUA e tenho certeza de que isso será, dificilmente, concluído em três meses. Eu não estou aqui para advogar um sistema presidencial, ou um sistema parlamentarista, e de fato eu confesso que às vezes sinto um pouco de confusão entre as caracteristicas próprias de cada um desses sistemas, porque cada um de nós tende a perceber no sistema que nós preferimos as suas qualidades, e no sistema que aceitamos os seus defeitos.

James Young é Diretor do Programa sobre Presidência do "Miller Center of Public Affairs", da Universidade de Virgínia, Estados Unidos, e conferencista do 2: Dia.

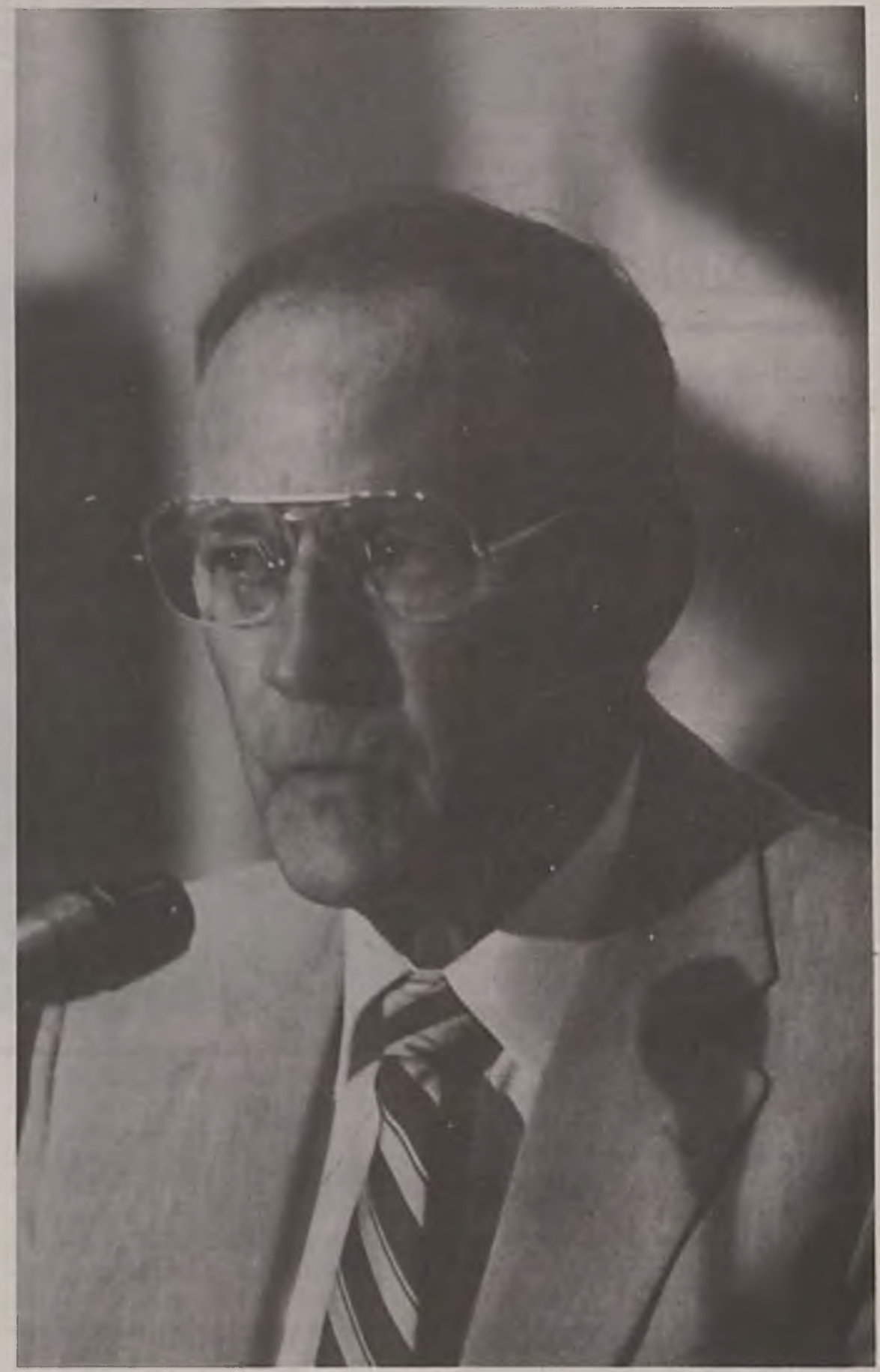


Portanto, no meu entender, não há uma definição única que seja universalmente aceita do Presidencialismo, e do Parlamentarismo. O que eu gostaria de fazer aqui não seria defender uma proposta geral do Presidencialismo, mas tentar explicar o que é o que não é o Sistema Presidencial nos EUA, qual a relação com o que está previsto na constituição que eu acho muito importante para as questões que a Nação brasileira enfrenta e por fim falarei, um pouco, sobre os termos e as condições sob as quais o sistema funciona nos EUA. Não sei o que vocês aprenderão disso e não tenho certeza que vão aprender muito, porém acho importante que eu tente explicar alguma coisa sobre a natureza do nosso sistema.

Primeiro, o que não é o Sistema Presidencjal na experiência dos americanos: muitas vezes um sistema presidencial é associado, em termos de conceito, com um poder legislativo ou corpo legislativo muito fraco. Não se pode falar do sistema presidencial nos EUA, nestes turmos. Uma presidência forte existe, coabita, conjuntamente, a um congresso, também, extremamente forte; e um legislativo bicameral extremamente forte. Deveras, sou de opinião que o Congresso nos EUA, possivelmente, é o mais forte, o mais ciumento do seu poder sobre política, sobre administração, sobre investigação da administração e conduta do executivo, do que qualquer outro no mundo.

Em parte, isso é consequiência do que está escrito na Constituição, é uma questão de como o Congresso conseguiu se organizar internamente para o exercício da ampla autoridade constitucional nele investido. O primeiro artigo da Constituição Americana define os poderes do legislativo: (a presidência vem depois). E, mesmo sendo a Constituição pequena, esce artigo é um dos mais longos. Não quero enumerar, porém, todos os poderes que são designados ao Governo Central, na Constituição Americana. Enuınero, no entanto, algumas prerrogativas do Congresso, designados como sendo poderes do legislativo: o poder de estabelecer impostos, de pagar dividas e tomar empréstimos, de regular o comércio exterior e o comércio entre os estados, de definir a política fiscal e orçamentária, criar novos estados, declarar guerra e prover a defesa, convocar e suprir o exército, a marinha, e reunir milícias, para repelir invasōes, reprimir insurreições, além de executar as leis da União.

O Congresso tem poderes executivos muito fortes na Constituição Americana. É o Congresso quem estabelece tudo que diz respeito à missão estatutária da parte executiva, a não ser à presidência. Todas as agências do governo federal dos EUA são criadas pelo Congresso: o Congresso vela e paga por elas, e elas têm que dar-lhe satisfaçôes do que faz. Esse poder é exercitado de uma maneira muito forte através do sistema de comitês do Congresso. Portanto, para todos os efeitos, todos os poderes de governo, e de estabelecer polí-

\begin{tabular}{|c|}
\hline \\
Todas as agências do \\
governo federal dos EUA \\
são criações do Congresso, \\
que vela por elas e paga \\
por elas. Elas têm que \\
prestar satisfaçōes ao \\
Congresso. Esse poder é \\
exercitado de uma maneira \\
muito forte através do \\
sistema de comitês do \\
Congresso. \\
\end{tabular}

ticas estão inscritos como atribuições do legislativo.

Por outro lado, a Presidência tem um rol de atribuições muito menor. $\mathrm{O}$ Presidente é o comandante-chefe das Forças Armadas, mas é o Congresso que tem o poder de estabelecer o regulamento para sua administração. Mesmo sendo o comandante-chefe, o Presidente não tem o poder de governar as Forças Armadas, esta é uma atribuição do Legislativo. O Presidente pode enviar e receber Embaixadores, isto é, o poder de reconhecer e conduzir a diplomacia. No entanto, poder de firmar tratados é repartidos com o Senado, e de- pende da aprovação por dois terços do mesmo. O Presidente pode nomear, com o consentimento de dois terço do Senado, os oficiais do corpo executivo e os ministros do governo. O Presidente detém todo poder executivo dado pela Constituição, com a ressalva de que, grande parte desse poder será repartido com o Congresso. Provavelmente, o mais importante poder, do Presidente, no sistema presidencial, seria o do veto condicional sobre os atos do legislativo. Digo condicional porque dois terço do Congresso pode repudiar o veto e essa ação terá força de lei. De certo modo esse é o poder legislativo do Presidente. Porém, nem o Presidente nem qualquer outro membro do Executivo pode ocupar uma cadeira no Legislativo, e somente comparecer ao plenário do Congresso por convite do Legislativo.

O Presidente, também, tem o poder e o direito de relatar ao Congresso, o estado da União e fazer-lhe recomendações. Esse é o seu poder de recomendar e propor políticas ao Legilastivo. Mas, quando se compara não somente o número de palavras, mas também o elenco de atribuiçōes sobre política, o poder fundamental de governo, nos EUA, está nas mãos do Congresso. $\mathrm{O}$ Presidente, porém, é independente do Congresso, seu mandato não pode ser reduzido ou interrompido a não ser por "altos crimes e má conduta", ou tenha sido julgado incompetente.

Outro motivo pelo qual o Congresso é forte, diz respeito à maneira como ele está organizado e desempenha suas funções. Creio que os estudiosos dessa questão concordam que uma associação coletiva tem uma capacidade limitada de incrementar políticas em plenário ou em debate. O Congresso, portanto, tem que ter pessoas que trabalhem, especialistas que ajudem a testar, discutir e elaborar toda a política pública.

Em 1985, o Congresso Americano desenvolveu os parâmetros do seu atual sistema de fortíssimo comitês, na Câmara e no Senado. Esses comitês são bastante especializados nas diferentes áreas legislativas. Eles supervisionam os vários Departamentos, iniciam, revêem e analisam a legislação. Além disso, o staff político do Congresso e dos congressistas cresceu muito nos últimos 20 anos. São mais de 10.000 pessoas trabalhando à disposição do Congresso, 


\section{IDÉIAS}

incluindo peritos em política externa, política financeira e orçamentária, etc.

Além disso, ao Congresso, também, foi dado poderes judiciais. Seus comitês podem requisitar documentos e informações, bem como compelir e exigir de pessoas testemunho em juizo. Podemos afirmar que, de certo modo, o Congresso possui agregados aos seus poderes legislativos, poderes judiciais, e executivos. Portanto, os fortes poderes do Congresso, nos Estados Unidos, são uma realidade viva e constitucional.

\section{PODERES DO PRESIDENTE}

Há uma segunda conotação na questão do Presidencialismo, ou que muitos pensam ser um atributo dos Sistemas Presidencialistas, mas que não é um fato dos EUA. Diz respeito à capacidade de legislar do Presidente. Falarei rapidamente sobre isso. O Presidente dos EUA não pode repudiar um ato do Legislativo, dissolver o Congresso, nem governar por decreto na ausência do Legislativo. O Presidente, então, tem um poder de veto realmente condicional. Não acatar ou desobedecer uma decisão do Congresso, é um ato inconstitucional e ele pode ser punido.

O Congresso é soberano para controlar os horários da suas sessões como também a sua organização interna e o Presidente não pode interferir nessas questões. Não há nada na Constituição Americana semelhante ao que é previsto em muitos sistemas parlamentaristas. como é o caso, da 5. República Francesa, em que, em situaçōes de emergência, o presidente pode governar por decreto. Nem o Presidente, nem o Congresso, nem as Forças Armadas c nenhum outro órgão constitutivo no governo americano tem direito constitucional para governar por decreto.

Falar do sistema presidencial dos Estados Unidos, é falar de um tipo de governo no qual um executivo é eleito, independentemente, com título de "Presidente", que forma um governo que administra, que toma à frente e determina que tipo de política a Nação deve adotar e seguir durante seu mandato, e ele será responsável, na próxima eleição, pelas conseqüências desta politica. Esse é, a meu ver, o significado e a natureza do sistema presidencial, nos EUA.
Estudiosos do sistema parlamentarista perceberão logo que da maneira como eu descrevi o sistema presidencialista dos EUA - a presidencia, o partido ou coalisão de partidos - está funcionando de forma muito assemelhada de seu sistema parlamentarista desenvolvido. O sistema presidencialista deve ser associado não a legislativo fraco mas a um legislativo forte. $\mathrm{O}$ sistema presidencialista é associado com um legislativo que tem realmente poderes de formular política que é associado com o sistema partidário fraco. O sistema partidário nos EUA é fraco e isso é associado no sistema presidencialista não com um legislativo fraco, ou mesmo um

$O$ presidente tem o poder executivo dado pela Carta, mas grande parte desse poder também está nas mãos do Congresso. $O$ mais importante poder do presidente é o do veto sobre os atos da legislatura, mas ainda assim é veto condicional.

judiciário fraco, pois este último no final tem um veto sobre qualquer ato do governo, seja administrativo, do Presidente ou do Congresso.

\section{O SISTEMA DE SEPARAÇÃO DOS PODERES}

No Brasil, no meu entender, há uma questão Importante, uma questão constitucional, quanto à estrutura do governo, às relações entre a Constituição e à natureza do sistema se Parlamentar ou Presidencial. Deve destacar que nos Estados Unidos, o sistema presidencial, mesmo que ele seja uma decorrência da
Constituição, ele não foi por ela estabelecido tal como o praticamos hoje. Vou explicar um pouco esse ponto.

O atual Sistema Presidencial Americano é, principalmente, uma criação do século XX, e ele não estava presente nem é característico do sistema americano existente em grande parte do século XIX. ele é então um desenvolvimento mais recente da evolução política dos EUA e não um sistema estipulado ou estabelecido pela Constituição de 1787.

É verdade, como já disse, que a Constituição estabeleceu as prerrogativas do Presidente, isto é, seu poder constitucional. Porém, não se encontra na Constituição, em lugar nenhum, a determinação de que cabe ao Presidente a iniciativa na elaboração e implementação da política pública.

De fato, os formuladores da Constituição visavam um sistema de controles e equilibrios, no qual nem um dos três poderes do governo seria capaz de assumir a liderança um sobre o outro, ao decidir os rumos da política pública.

Esse sistema de controles e equilíbrios, é às vezes, denominado de sistema de separação dos Poderes.

A "Separação de Poderes", não possui uma descrição precisa, porque, como já indiquei, pela Constituição, o Presidnete tem alguns poderes legislativos; o Congresso tem alguns poderes executivos e até poderes judiciários, e é claro, a Suprema Corte tem que estar envolvida na formulação da política, já que ela tem o poder de revisão final sobre a constitucionalidade da legislação e atos do Presidente ou de seu governo.

Uma descrição mais precisa seria de que a Constituição estabelece instituições separadas, que repartem entre si o poder de formular a política. Essa separação é tão severa que um Deputado ou um Senador não pode ocupar um cargo do executivo durante a vigência de seu mandato, nem mesmo em caso de renúncia. Um Deputado não pode ter cadeira no Senado, simultaneamente, a seu cargo de Deputado e vice-versa. A separação de poderes é completa, mas o poder é repartido. Pelo sistema de controles e equilibrios pretende-se permitir que qualquer um dos poderes, ou qualquer interesse envolvido nas representações destes três poderes, possa iniciar, ou participar da política. Po- 


\section{IDÉIAS}

rém, torna-se muito difícil que um deles imponha a sua vontade sobre a política pública sem o consentimento dos outros dois.

É muito difícil no sistema americano, o Presidente conseguir fazer alguma coisa a não ser que ele conte com o consentimento, muitas vezes por ato positivo, do Congresso. É muito difícil para o Congresso conseguir alguma ação ou impor uma política pública contra determinada posição do Presidente. É impossível para o Presidente, para o Senado, ou para a Câmara, mesmo se eles concordem entre si, dar continuidade a uma diretriz política, se a Suprema Corte a invalidou. Então, o poder de veto de um sobre o outro, caminha junto com o poder de formular a política. Não se trata de uma falha de julgamento, nem um ponto de estimulo à controvérsia, mas, ao contrário, trata-se de uma norma explicita de convivência e repartição dos poderes no sistema presidencial de governo. Essa é uma norma intencional e não uma falha de julgamento, sobre quem deveria dominar o poder dentro de um sistema de governo.

Essa escolha foi feita conscientemente e deixada como herança às futuras geraçōes: estabelecer um sistema onde qualquer um poderia iniciar ou carregar o fardo, de organizar o consenso e o apoio para uma determinada politica dentro do sistema. Havia um sentimento profundo entre os constituintes, de que na Constituição não deveria haver nenhum dispositivo que permitisse no futuro, uma instituição, classe ou cargo ter a última palavra ou o controle crítico sobre uma determinada politica pública. Eles acham que isso colocaria em perigo a causa da liberdade.

Sentia-se, naquela época, que era desejável que a contenção, ou o conflito em torno da política, entre os segmentos do governo, e entre as bases por eles representadas fosse debatido, e que a iniciativa do governo quanto a políticas públicas só deveria ser incrementada a partir do consenso, de concordância, ou do compromisso entre as diversas partes do Congresso.

O que os elaboradores da Constituição deixaram em aberto foi: como se deveria chegar a esse consenso? Quem lideraria? Através de que maneira? E através de que processo? Então a Constituição, de certo modo, estabeleceu um programa mas não predeterminou o seu resultado em termos de um sistema fosse ele parlamentar, presidencial, ou alguma mistura dos dois.

\section{O SISTEMA DE SEPARAÇÃO DOS PODERES}

Chego à minha terceira observação sobre o sistema americano, de que a Constituição permitiu a existência, durante um período pregresso da história americana de algo semelhante a um sistema parlamentar, neste século, um sistema bem mais parecido com o sistema presidencialista. A Constituição permi-

\begin{tabular}{|c|}
\hline \\
A separação entre os \\
poderes é muito dura: um \\
deputado não pode ocupar \\
um cargo do Executivo ou \\
ser nomeado para um \\
cargo durante seu mandato \\
parlamentar, nem mesmo \\
se ele renunciar. É \\
completa a separação, mas \\
o poder é repartido. $\hat{E}$ \\
equilibrio de poderes.
\end{tabular}

tiu que a iniciativa de poder, passasse de um lado para outro, sem que ela própria se modificasse.

Quero dizer algumas breves palavras sobre o Sistema Parlamentar nos EUA. Se nós procurássemos os exemplos principais, olharíamos para o tempo de Jefferson, isto é, 1800 a 1807 quando o primeiro sistema partidário foi desenvolvido antes, no tempo que foi escrita a Constituição, não havia partidos. Talvez isto tenha facilitado o trabalho dos constituintes. Os partidos só se formaram em seguida, ao redor da controvérsia sobre a política de desenvolvimento do governo e a questão de qual o rumo que a Nação deveria tomar. O par- tido de Jefferson derrotou o partido de Hamilton, e permaneceu 20 anos no poder. A partir de 1800 ele pôde implementar seu programa de desenvolvimento da nova Nação, que não era de industrialização, mas expansão do território, não de adotar o protecionismo, mas desenvolver indústrias nacionais e usar o déficit para aumentar os recursos e o território geopolítico da nova Nação. Esse programa foi desenvolvido, me parece, exatamente como no sistema parlamentar inglês, porque a maioria do partido no Congresso iniciava e aprovava a legislação e formava o governo; todos os ministros de Jefferson pertenciam ao legislativo e eles eram membros do mesmo Partido. $\mathrm{O}$ seu principal auxiliar era James Madison que era lider do Partido no Congresso.

Os membros do Partido, numa reunião denominada o "caucus convencional" decidiram que seu lider no Congresso seria nomeado para a Presidência. Thomas Jefferson no segundo termo, James Madison, James Monroe e, depois John Quincy Adams, foram todos escolhidos presidente pelo Partido que representavam no Congresso. $\mathrm{E}$ isso parece realmente com um sistema parlamentar. O partido forma o governo, estabelece o programa de governo e, nas eleiçōes, é o responsável pelas conseqüências das suas açōes. $\mathrm{O}$ Partido de Jefferson recebeu votos de confiança várias vezes, e na vez de Monroe, todos os votos eleitorais foram para o candidato do governo, a oposição não teve nenhum êxito. Os Estados Unidos tinham um sistema monopartidário. O outro exemplo é do final desse mesmo século. No auge da industrialização americana, depois da guerra civil, depois da reconstrução de 1880 até o final do século, quando tivemos o que alguns chamam de a "época dourada" de governo congressual. Nesta época o líder do Congresso era chamado de "Primeiro-Ministro" ou de "Tzar" pela impressa americana e correspondia ao cargo mais importante da União. $O$ Congresso através da oligarquia, do Partido Republicano estabeleceu o capitalismo como política da nação, suprimiu os sindicatos porque era a favor da mão-de-obra barata, protegeu o mercado com tarifas alfandegárias elevadas, encorajou a imigração, forneceu os meios para que as ferrovias pudessem ser construídas e assegurou um mercado cativo para desenvolver as in- 


\section{IDÉIAS}

dústrias domésticas. Tudo isso foi feito sem grande participação do Presidente. O Presidente era um funcionário do "Primeiro-Ministro", que estava dentro da Câmara dos Deputados. O Congresso supervisionava a administração das suas políticas através do sistêma de Comitê do Congresso. Durante grande período da história americana confiamos, desenvolvemos, utilizamos um sistema parlamentar, sem nunca modificar a Constituição de maneira significativa. Uma importante exceção a este "sistema parlamentarista", corresponde ao período da guerra civil, quando Abrão Lincoln era o presidente, ele implementou um sistema bem diferente.

\section{A PERSPECTIVA DO PRESIDENCIALISMO AMERICANO}

$\mathrm{O}$ século XX assistiu ao enfraquecimento desse "parlamentarismo" e o fortalecimento do sistema presidencial. O enfraquecimento dos partidos é o que pode explicar como a presidencia cresceu e assumiu funções que seriam do partido, num sistema parlamentar. A Presidência e não os partidos deve formular e guiar a política e ser responsável por ela perante o eleitorado. Obviamente, que o papel dos EUA nas duas guerras mundiais, a emergência da América como um poder internacional e um poder nuclear, com compromissos mundiais, a Grande Depressão de 1929 tudo isso tem a ver com as mudanças do sistema e as novas atribuiçōes assumidas pelo Presidente. Não sabemos durante quanto tempo o sistema presidencial vai durar ou que outro desenvolvimento ou modificação tomará seu lugar. Há muita discussão nos EUA, hoje, duzentos anos depois da nossa Constituição, sobre os problemas que existem no sistema presidencialismo e no governo presidencial. E há um atrativo novo, indicando na direção de um sistema parlamentar. A questão, então será de fortalecer os partidos. Não sei se eles podem ser ressuscitados na maneira como funcionaram em épocas anteriores, mas eu acho que pode-se dizer com certeza que o sistema presidencialista americano vai se modificar e, possivelmente, já está se modificando.

O que assistimos nos últimos 10 ou 15 anos foi a reativação do poder e da autoridade do Congresso num esforço

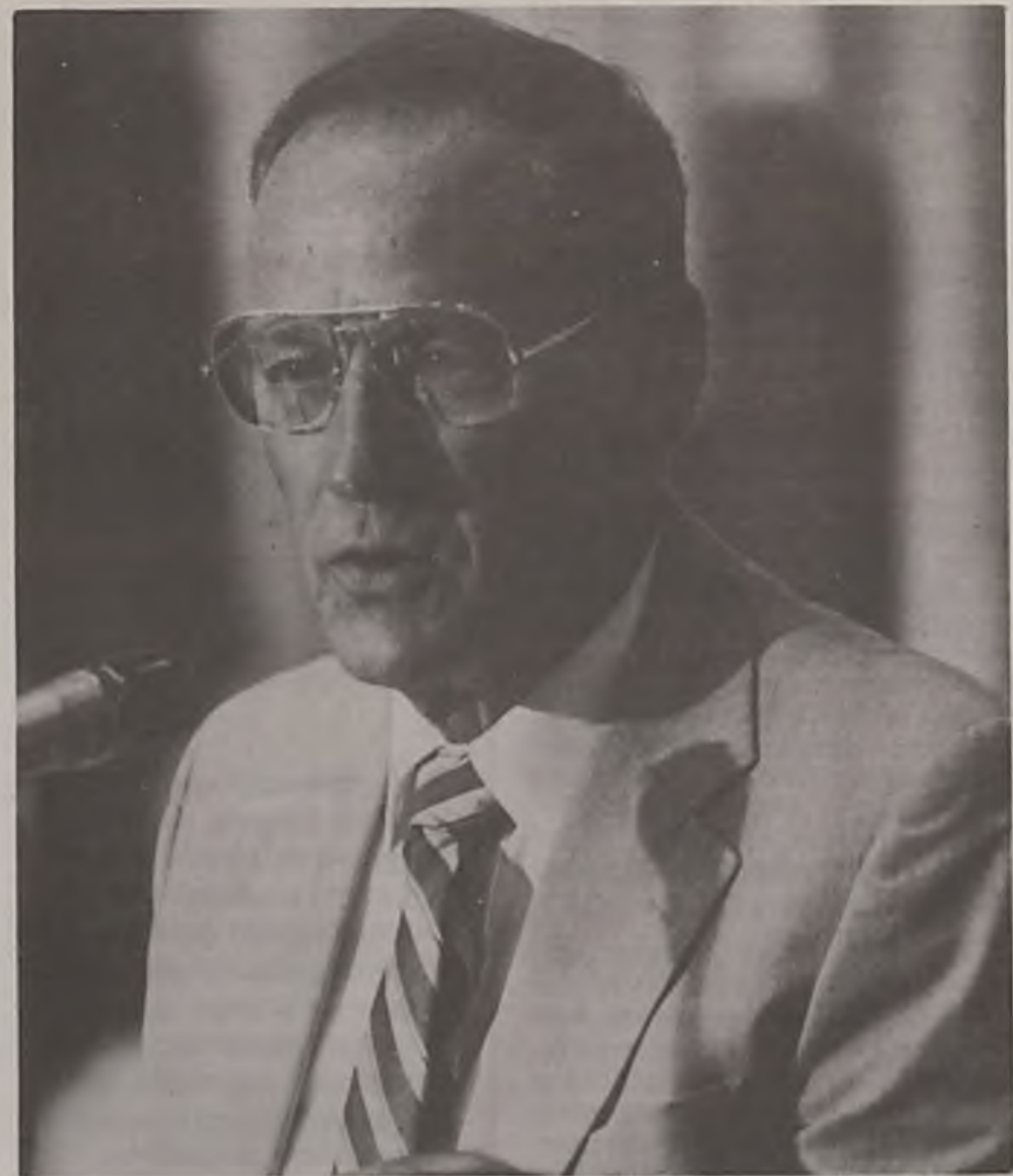

de policiar a presidência, vigiar a administração das suas políticas, e interferir com uma voz poderosa na formulação das politicas doméstica e internacional.

Será interessante observar o resultado das atuais investigaçōes sobre a ação do Presidente na Casa Branca, para ver se isso vai se tornar um caso no qual o Presidente assumiu uma prerrogativa que ele não tem, ou que outros em nome dele assumiram prerrogativas que não tinham, quer dizer se eles infringiram ou não a vontade do Congresso. Se isso for comprovado, podem ser processados pelo Congresso.

Esses acontecimentos, os escândalos de Nixon, a perda de confiança que tivemos no Vietnam, tudo isso renovou o interesse em reduzir o poder do Presidente e voltar a um sistema mais próximo de um sistema de governo, no qual o Congresso é um sócio majoritário do Presidente.

O sistema presidencial não pode sobreviver sem o assentimento do Congresso. Grande parte da autoridade do Presidente é oriunda da delegação feita a ele por atos específicos do Congresso, podendo, portanto, retirá-la. No momento atual ele está nas condiçōes de fazer isso de maneira lenta e incerta. O sistema presidencial também não poderá sobreviver se o presidente não puder demonstrar que ele não somente tem o consentimento do legislativo, mas que a sua política reflete o consenso do país, além dos membros do seu partido. Nessas condições eu vejo um recuo do sistema presidencial nos EUA, mas não o enfraquecimento da presidência. A presidencia vai se manter forte; o Congresso vai se manter forte, mas a liderança poderá sair das mãos da Presidência. 